\title{
Willingness to accept risk in the treatment of rheumatic disease
}

\author{
Bernie J O'Brien, Judith Elswood, Andrei Calin
}

\begin{abstract}
Study objective-The aim was to assess patients willingness to accept mortal risk in the drug treatment of chronic rheumatic disease.
\end{abstract}

Design-A non-random sample of consecutive patients were interviewed with a standardised survey instrument.

Setting - The study took place in the Royal National Hospital for Rheumatic Diseases, Bath, UK.

Patients-100 consecutive in- and outpatients aged 65 or less were interviewed, 50 with rheumatoid arthritis and 50 with ankylosing spondylitis. Mean age was 48 years with mean disease duration of 14 years. The rheumatoid arthritis group was mainly female $(84 \%), v 26 \%$ in the ankylosing spondylitis group.

Measurements and main results-Risk preferences were elicited using the method of standard gamble in the context of a hypothetical new drug. Patients indicated the maximum percentage probability of mortality they regarded as acceptable to achieve four different levels of benefit: total cure $(20.7 \%)$, relief of pain $(16.9 \%)$, relief of stiffness $(13 \cdot 1 \%)$, return to normal functioning (14.5\%). Rheumatoid arthritis patients displayed a higher $(p<0.05)$ willingness to accept risk than ankylosing spondylitis patients for all gambles except relief of stiffness. Analysis of variance indicated that willingness to accept risk decreases with the duration of disease and increases with reductions in self assessed health status.

Conclusions-Evaluative methods such as standard gamble can elicit useful riskbenefit preference data from patients to assist those who manage clinical risks.

Health Economics Research Group, Brunel University, Uxbridge, Middlesex UB8 3PH, United Kingdom B J O'Brien

Royal National Hospital for

Rheumatic Diseases,

Bath, United

Kingdom

J Elswood

A Calin

Correspondence to: Dr O'Brien
Risk assessment of medicines can be divided into two separate tasks of risk estimation and risk evaluation. $^{1}$ The former utilises the available epidemiological data from clinical trials and postmarketing surveillance to determine the probability of a specific adverse drug reaction occurring in a particular patient population during a period of time. The latter is the judgemental process of balancing the therapeutic benefit of the drug against its estimated risk. The resolution of such "acceptable risk" decision problems in the management of drugs requires the decision makers-be they doctors, patients or regulators-to make a trade off, implicitly or explicitly, between risk and benefit. $^{2}$ One experimental approach for eliciting risk-benefit preferences is the "standard gamble" method recently used in the evaluation of oral gold therapy for rheumatoid arthritis. ${ }^{3}$ The aim of the present study is to utilise this approach to examine patients' stated willingness to accept mortal drug risk to achieve a range of hypothetical therapeutic benefits in the treatment of two chronic rheumatic diseases: (1) rheumatoid arthritis, the prototypic chronic inflammatory disease affecting primarily older women; (2) ankylosing spondylitis, also characterised by pain, inflammation, and stiffness but generally affecting a younger, more mobile, predominantly male population.

\section{Methods}

A sample of 100 consecutive in- and outpatients (quota 50 rheumatoid arthritis, 50 ankylosing spondylitis) attending the Royal National Hospital for Rheumatic Diseases and aged 65 or under were selected for interview. Eligible patients were either attendees of a weekly outpatient clinic or inpatient cases in the period September 1988 to April 1989. The age restriction was imposed because it was thought that older patients may have difficulty understanding the interviews and might be more concerned about questions dealing with possible death. No selected patient refused to be interviewed. The interview had two major components; the first was a series of hypothetical treatment decisions using the method of the standard gamble and the second was a series of demographic and health status questions including the Nottingham Health Profile and three visual analogue scales.

STANDARD GAMBLES

The method of the standard gamble is a simple framework for analysing what value an individual places on choices involving different levels of benefit and risk. ${ }^{4-6}$ Its origins lie in an axiomatic and normative theory of choice which requires individuals to choose between risky alternatives on the basis of expected utilities-ie, the relative value of outcomes weighted by their probabilities. ${ }^{7}$ Among other applications it has been used to assess the willingness of rheumatoid arthritis patients to accept treatment risks in clinical trials of oral gold (auranofin). ${ }^{3}$ The method is illustrated in the figure, where a person is confronted with two choices: Choice $\mathbf{A}$ (taking the drug) has two possible consequences, a probability $1-p$ that it will produce a specified health benefit $(\mathrm{X})$ and a probability $p$ that it will result in death (eg, 99\% chance of cure, $1 \%$ chance of death). Choice $B$ is not to take the drug and to remain in the current health state. The 


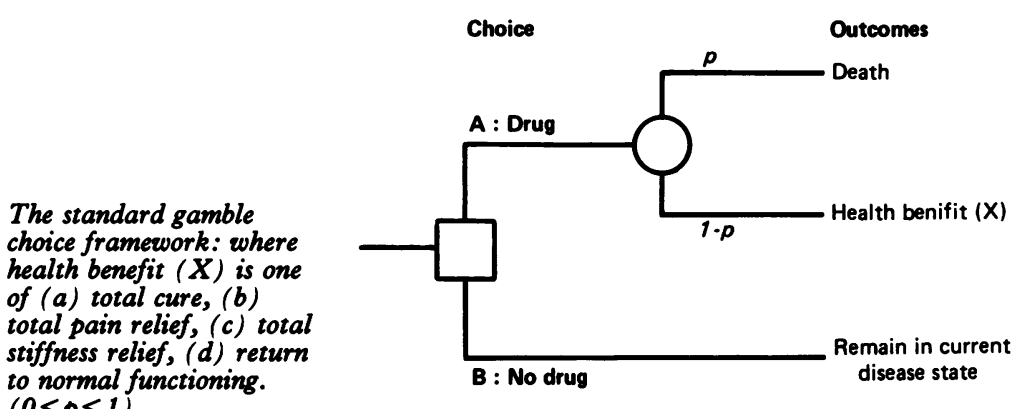

method elicits the maximum probability of mortality, $p$, that would persuade the patient not to take the drug. The method therefore offers an implicit valuation of the current health state relative to the two possible outcomes from the gamble.

To introduce the questions on willingness to accept risk, the interviewer asked patients to consider the ways in which their disease affects their life and their family. Then patients were presented with a simple standard gamble choice problem:

"Now, I'd like you to imagine that there is a new rheumatoid arthritis (ankylosing spondylitis) medication available. It is a very powerful and effective drug, but it carries substantial risk. If you take this medication, it will either completely cure you of your rheumatoid arthritis (ankylosing spondylitis) or it will kill you.

Suppose that $\mathbf{5 0}$ percent of the people who take the new medication are cured of their rheumatoid arthritis (ankyosing spondylitis) and 50 percent die. Would you risk taking the new medication?"

Starting from the response to this question the interviewer varied the probability of death, in an iterative way, to find the maximum acceptable risk for the therapeutic benefit being offered. Respondents completed four standard gambles which differed only in terms of therapeutic pay off (ie, health benefit $X$ in the figure) which was one of (a) total cure, (b) total relief of pain, (c) total relief of stiffness, (d) return to normal functioning.

\section{HEALTH STATUS MEASURES}

The Nottingham Health Profile is a widely used and well validated method of assessing health related quality of life. ${ }^{89}$ Patients are required to give yes/no answers to 38 simple statements relating to six domains of energy, pain, emotional reactions, sleep, social isolation, and physical mobility. All statements relate to limitations on physical, social or emotional functioning. Statements in each domain have relative weights and domain scores lie in the range 0 to 100 , with higher scores denoting greater problems. No global Nottingham Health Profile score is available but the percentage of total statements affirmed has been reported as an overall quality of life indicator. ${ }^{10}$ Subjects also completed three $10 \mathrm{~cm}$ line visual analogues to indicate their current health state, level of pain, and level of stiffness. Visual analogue scores lie in the range 0-100. Extreme markers were: health status, $0=$ "excellent health", $100=$ "very poor health"; pain, $0=$ "no pain", $100=$ "excruciating pain"; stiffness, $0=$ "no stiffness or restriction of mobility", $100=$ "extreme stiffness and restriction of mobility".

\section{STATISTICAL METHODS}

Differences between means of continuous variables were tested by $t$ test, differences between proportions by $\chi^{2}$ test, and differences between Nottingham Health Profile scores by the non-parametric Mann-Whitney test.

The primary hypotheses to be tested were: (1) For both diagnoses, what is the relative value of total cure, pain relief, stiffness relief or return to normal functioning, as indicated by patients' willingness to accept mortal risk? (2) Does willingness to accept risk, for each therapeutic benefit, differ between rheumatoid arthritis and ankylosing spondylitis patients? (3) Are patients
Table I Demographic and health characteristics of sample: rheumatoid arthritis (RA) and ankylosing spondylitis (AS) patients. Values are mean (SEM) or

\begin{tabular}{|c|c|c|c|c|}
\hline & $\begin{array}{l}\text { All } \\
(n=100)\end{array}$ & $\begin{array}{l}R A \text { patients } \\
(n=50)\end{array}$ & $\begin{array}{l}A S \text { patients } \\
(n=50)\end{array}$ & p value \\
\hline \multirow{3}{*}{$\begin{array}{l}\text { Age (years) } \\
\text { Age left full time education (years) } \\
\text { Duration of disease (years) } \\
\text { Nottingham Health Profile } \\
\text { Energy } \\
\text { Pain } \\
\text { Emotional reactions } \\
\text { Sleep } \\
\text { Social isolation } \\
\text { Physical mobility }\end{array}$} & \multicolumn{4}{|c|}{ mean (SEM) } \\
\hline & $\begin{array}{l}48.2(1.2) \\
17.3(0.5) \\
13.5(0.9)\end{array}$ & $\begin{array}{l}50.9(1.7) \\
17.0(0.7) \\
13.3(1.4)\end{array}$ & $\begin{array}{l}45.4(1.7) \\
17.6(0.5) \\
13.7(1.2)\end{array}$ & $\begin{array}{l}0.02 \\
0.5 \\
0.2\end{array}$ \\
\hline & $\begin{array}{l}49 \cdot 3 \\
46 \cdot 9 \\
21 \cdot 0 \\
35 \cdot 7 \\
12 \cdot 9 \\
40 \cdot 1\end{array}$ & $\begin{array}{l}61 \cdot 8 \\
53 \cdot 1 \\
27 \cdot 3 \\
41 \cdot 0 \\
14 \cdot 2 \\
48 \cdot 7\end{array}$ & $\begin{array}{l}36 \cdot 7 \\
40 \cdot 7 \\
14 \cdot 6 \\
30.4 \\
11.7 \\
31.5\end{array}$ & $\begin{array}{l}0.002 \\
0.05 \\
0.002 \\
0.08 \\
0.05 \\
0.001\end{array}$ \\
\hline $\begin{array}{l}\text { Visual analogues } \\
\text { Health status } \\
\text { Pain } \\
\text { Stiffness }\end{array}$ & $\begin{array}{l}46 \cdot 3(2 \cdot 4) \\
52 \cdot 1(2 \cdot 8) \\
57 \cdot 6(2 \cdot 5)\end{array}$ & $\begin{array}{l}51.4(3.4) \\
57.1(3.8) \\
58.2(3.8)\end{array}$ & $\begin{array}{l}41 \cdot 3(3 \cdot 1) \\
47 \cdot 1(3.9) \\
58 \cdot 2(3 \cdot 8)\end{array}$ & $\begin{array}{l}0.03 \\
0.07 \\
0.8\end{array}$ \\
\hline & \multicolumn{4}{|c|}{$n(\%)$} \\
\hline $\begin{array}{l}\text { Sex: } \\
\text { Male } \\
\text { Female }\end{array}$ & $\begin{array}{l}45(45) \\
55(55)\end{array}$ & $\begin{array}{r}8(16) \\
42(84)\end{array}$ & $\begin{array}{l}37(74) \\
13(26)\end{array}$ & $<0.001$ \\
\hline $\begin{array}{l}\text { Experienced a serious ADR': } \\
\text { Once } \\
\text { More than once } \\
\text { Never } \\
\text { Other serious health problem }\end{array}$ & $\begin{array}{l}26(26) \\
37(37) \\
37(37) \\
33(33)\end{array}$ & $\begin{array}{l}14(28) \\
20(40) \\
16(32) \\
16(32)\end{array}$ & $\begin{array}{l}12(24) \\
17(34) \\
21(42) \\
17(34)\end{array}$ & $\begin{array}{l}0.6 \\
0.8\end{array}$ \\
\hline
\end{tabular}

a NHP domain scores have a range of 0-100. A higher score denotes greater problems. Statistical differences tested using non-parametric Mann-Whitney test

bee text for definitions of visual analogues

c $\mathrm{ADR}=$ adverse drug reaction 
who state a greater willingness to accept risk characterised by greater duration of disease or poorer self assessed health status?

\section{Results}

Demographic and health status data are given in table I. The mean age of patients was 48 years with a disease duration of 14 years. Rheumatoid arthritis patients were generally older than ankylosing spondylitis patients $(p=0.02)$ and the rheumatoid arthritis sample was $84 \%$ female compared with $26 \%$ in the ankylosing spondylitis sample. Overall, $37 \%$ of patients (rheumatoid arthritis $40 \%$, ankylosing spondylitis $34 \%$ ) claimed they had experienced more than one serious adverse drug reaction and 33\% (rheumatoid arthritis $32 \%$, ankylosing spondylitis $34 \%$ ) reported some form of comorbidity. Visual analogue scores indicated that rheumatoid arthritis patients rated their general health status lower than ankylosing spondylitis patients $(p=0.03)$ and were generally experiencing more pain $(p=0.07)$ but a very similar level of stiffness. Nottingham Health Profile scores indicated that rheumatoid arthritis patients were experiencing greater problems with physical mobility $(p=0.001)$, energy $(p=0.002)$, and emotional reactions $(p=0.002)$. Experience of pain, social isolation, and sleep was worse in the RA group but of marginal statistical significance $(0.05 \leqslant \mathrm{p} \leqslant 0.01)$.

Results from the four standard gambles are presented in table II. For all patients combined, the mean "maximum acceptable risk" to achieve total cure was $20.7 \%$; relief of pain $16.9 \%$, relief

Table II Willingness to accept risk of mortality to achieve therapeutic benefit. Values are mean percentages with $95 \%$ confidence intervals

\begin{tabular}{|c|c|c|c|}
\hline \multirow[b]{2}{*}{ Therapeutic benefit } & \multicolumn{3}{|c|}{$\begin{array}{l}\text { Maximum acceptable risk of mortality } \\
\text { to achieve therapeutic benefit }\end{array}$} \\
\hline & All & $R A$ patients & $A S$ patients \\
\hline $\begin{array}{l}\text { Total cure } \\
\text { Relief of pain } \\
\text { Relief of stiffness } \\
\text { Return to normal functioning }\end{array}$ & $\begin{array}{l}20 \cdot 7(15 \cdot 4,26 \cdot 0) \\
16 \cdot 9(12 \cdot 0,21 \cdot 8) \\
13 \cdot 1(9 \cdot 2,17 \cdot 0) \\
14 \cdot 5(10 \cdot 2,18 \cdot 8)\end{array}$ & $\begin{array}{l}26 \cdot 8^{\star}(18 \cdot 7,34 \cdot 8) \\
22 \cdot 6^{\star}(15 \cdot 0,30 \cdot 2) \\
15 \cdot 2 \quad(9 \cdot 1,21 \cdot 3) \\
19 \cdot 6^{\star}(12 \cdot 5,26 \cdot 7)\end{array}$ & $\begin{array}{r}14 \cdot 5(8 \cdot 0,21 \cdot 0) \\
11 \cdot 3(5 \cdot 8,16 \cdot 8) \\
10 \cdot 9(6 \cdot 2,15 \cdot 6) \\
9 \cdot 2(4 \cdot 5,13 \cdot 9)\end{array}$ \\
\hline
\end{tabular}

Table III Univariate analysis of willingness to accept risk to achieve cure: all patients

\begin{tabular}{|c|c|c|c|}
\hline \multirow{2}{*}{\multicolumn{2}{|c|}{ Method of analysis }} & \multicolumn{2}{|c|}{$\begin{array}{l}\text { Maximum acceptable risk } \\
\text { of mortality to achieve cure: }\end{array}$} \\
\hline & & $n$ & Mean percent $(95 \% \mathrm{CI})$ \\
\hline (a) & $\begin{array}{l}\text { Self-assessed health status I: } \\
\text { Visual analogue } \\
\text { (0=excellent, } 100=\text { very poor) } \\
0-24 \\
25-49 \\
50-74 \\
75-100\end{array}$ & $\begin{array}{l}21 \\
37 \\
29 \\
12\end{array}$ & $\begin{array}{l}15 \cdot 9(7 \cdot 1,24 \cdot 7) \\
18 \cdot 3(9 \cdot 5,27 \cdot 1) \\
20 \cdot 6(10 \cdot 9,30 \cdot 2) \\
36 \cdot 8(18 \cdot 2,55 \cdot 4)\end{array}$ \\
\hline (b) & $\begin{array}{l}\text { Self-assessed health status II: } \\
\text { Nottingham Health Profile } \\
\text { (percent of statements affirmed)^ } \\
0-24 \\
25-49 \\
50-74 \\
75-100\end{array}$ & $\begin{array}{r}29 \\
38 \\
29 \\
3\end{array}$ & $\begin{array}{ll}12 \cdot 7 & (4 \cdot 7,20 \cdot 7) \\
21.6 & (13 \cdot 2,30 \cdot 0) \\
25 \cdot 4 & (5 \cdot 4,36 \cdot 4) \\
41 \cdot 7 & (4 \cdot 0,79 \cdot 3)\end{array}$ \\
\hline (c) & $\begin{array}{l}\text { Duration of disease } \\
<15 \text { years } \\
15-30 \\
>30 \\
\end{array}$ & $\begin{array}{r}57 \\
36 \\
6 \\
\end{array}$ & $\begin{array}{rr}24.0 & (16.6,31.4) \\
17.4 & (9.4,25.4) \\
9.2 & (0.6,19.0)\end{array}$ \\
\hline
\end{tabular}

* Higher percentage affirmation of statements indicates poorer health status of stiffness $13 \cdot 1 \%$, and return to normal functioning $14.5 \%$. Analysis of variance indicated differences between the two disease groups, with rheumatoid arthritis patients displaying a significantly higher maximum acceptable risk on all gambles except relief of stiffness (eg, return to normal functioning: rheumatoid arthritis $19 \cdot 6^{\circ}$, ankylosing spondylitis $9 \cdot 2 \%, \mathrm{p}=0.02$ ).

Estimated maximum acceptable risk for cure is stratified by self assessed health status and by duration of disease for pooled diagnosis data in table III. Although maximum acceptable risk estimates have large confidence intervals, the data are consistent with the hypothesis that patients with a poorer self assessed health status, measured either by visual analogue or Nottingham Health Profile, have a greater willingness to accept risk. In addition, patients who had been diseased for a greater number of years generally gave lower maximum acceptable risk responses.

\section{Discussion}

Deciding between the treatment options for chronic rheumatic disease requires a balancing of risk against benefit; the health gains from drug therapy may be palliative or disease modifying ${ }^{11}$ but they are only achieved at the risk of adverse events, including death. If therapeutic decision making is to reflect patient preferences then clinicians require a greater understanding of the ways patients perceive and react to the potential risks and benefits of therapy. The experimental method of this study, using hypothetical scenarios and choices, is a useful framework for eliciting patient's views. The precise estimates of maximum acceptable risk responses should be viewed with caution; they are based on a small sample of patients from one tertiary referral centre, and extrapolation to other groups or inclusion in "real life" decisions would be unwise. Results are indicative and illustrative of the method, providing empirical markers for discussion and further study.

For this sample of patients with rheumatic disease, responses indicate that the average individual is prepared to accept a 1 in 5 chance of immediate death from a drug which offers a complete cure from the disease. Are such results reliable and valid? Although reliability in the form of within study reproducibility (ie, test - retest method) was not assessed in this study, the interstudy reproducibility of results for rheumatoid arthritis patients is encouraging; the $27 \%$ maximum acceptable risk for total cure from our 50 rheumatoid arthritis patients is identical to that found in an earlier US study of 247 rheumatoid arthritis patients using the standard gamble method. ${ }^{3}$

Assessing the validity of expressed preferences for risk taking is more problematic because the "true" preferences that individuals hold cannot be directly observed, only indirectly revealed by the choice they make. While treatment risks in the order of $20 \%$ are commonly accepted for major acute interventions such as heart transplantation $\left(80 \%\right.$ survival at one year $\left.{ }^{12}\right)$, similar risks for non-life-threatening diseases are not commonly observed, although there may be a willingness to accept increased mortal risk to achieve 
improvements in health related quality of life. ${ }^{13}$ The nature of this trade off between quantitative and qualitative aspects of health is central to the evaluation of treatment risks.

Standard gamble responses indicate the relative value patients attach to their current health status when compared with the therapeutic pay off of the gamble. Maximum acceptable risk responses for each therapeutic pay off indicate that pain is perceived as more of a problem than stiffnessboth groups were prepared to risk more to rid themselves of pain. However, for ankylosing spondylitis patients the difference between maximum acceptable risk for pain $(11.3 \%)$ and stiffness relief $(10.9 \%)$ is less pronounced, which is consistent with previous data on ankylosing spondylitis symptoms. ${ }^{14}$ Results also suggest that rheumatoid arthritis is more disruptive of normal functioning than ankylosing spondylitis; rheumatoid arthritis patients were willing to risk more to return to normal functioning than to relieve stiffness, in contrast to ankylosing spondylitis patients.

The observed association between self assessed health status and maximum acceptable risk responses was an expected result and an indication of convergent validity between a health utility measure such as standard gamble and a health profile measure such as the Nottingham Health Profile. An unexpected finding was the association between disease duration and maximum acceptable risk responses, which further analysis indicated was independent of patient age. One explanation is that patients adapt to their illness over time, a process which serves to diminish the relative value of the therapeutic pay offs from treatment gambles. But this issue would benefit from further study because Thompson ${ }^{3}$ has found the opposite association and argued that risk preference would increase with disease duration due to patients' 'increasing desperation" with their disease.

There are a number of methodological problems associated with this type of survey research. ${ }^{15}$ They include problems of how hypothetical choices are presented or framed for patients, the confounding influences of subjects' attitudes towards gambling itself, the necessary simplicity and abstraction of the decisions to be made, and the extent to which respondents are able to process dispassionately the numerical information put before them. Indeed, one of the constraints upon the further development of this approach is a poor understanding of how patients and the public perceive the risks of medicine. ${ }^{16} 17$
Patient preferences are playing an increasing role in therapeutic decision making and studies have shown systematic differences in the risk perceptions and risk-benefit preferences across patient groups and between patients and clinicians. ${ }^{18}$ In the management of drugs, by regulators or clinicians, it has long been recognised that what may be an acceptable risk for one patient or disease group may not be acceptable for another. But hitherto there have been very few systematic attempts to elicit patient preferences as one input into this decision process. The methods used in this study offer one way forward and can be adapted to assess other difficult treatment choices where symptomatic relief is offered at the risk of some fatal or non-fatal adverse event.

We are grateful to David McGeoch and Katherine Weeks for their help with the interviews and to Paul Slovic and Mark Thompson for comments. We also thank Denis Burley and the Risk Assessment of Drugs-Analysis and Response (RAD-AR) programme for financial assistance.

1 Royal Society. Risk assessment: report of a Royal Society working party. London: The Royal Society, 1983.

2 Lane DA, Hutchinson TA. The notion of "acceptable risk": the role of utility in drug management. $f$ Chron Dis 1987; 40: 621-5.

3 Thompson MS. Willingness to pay and accept risks to cure chronic disease. Am f Public Health 1986; 76: 392-6.

4 Llewellyn-Thomas HA, Sutherland HJ, Tibshirani R, et al. The measurement of patient values in medicine. Medical Decision Making 1982; 2: 449-62.

5 Torrance GW. Measurement of health state utilities for economic appraisal. $\mathcal{F}$ Health Econ 1986; 5: 1-30.

6 Read JL, Quin RJ, Berwick DM, et al. Preferences for health outcomes. Medical Decision Making 1984; 4: 315-29.

7 von Neumann, Morgenstern $O$. Theory of games and economic behaviour, 2nd ed. Princeton NJ: Princeton University Press, 1947

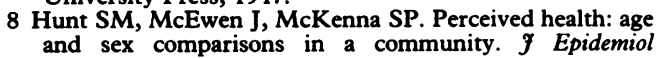
Community Health 1984; 38: 156-60.

9 Hunt SM, McEwen J, McKenna SP. Measuring health status. Beckenham, Kent: Croom Helm, 1986.

10 O'Brien BJ, Buxton MJ, Ferguson BA. Measuring the effectiveness of heart transplant programmes: quality of life data and their relationship to survival analysis. $\mathcal{F}$ Chron Dis data and their relationship to
1987; 40 (suppl 2): 137-53.

11 Kushner I. Does aggressive therapy for rheumatoid arthritis affect outcome? $\Im$ Rheumatol $1989 ; 16: 1-4$.

12 Mulcahy D, Wright C, Mockus L, Yacoub M. Cardiac transplantation in severely ill patients requiring intensive support in hospital $\mathrm{Br}$ Med $\mathcal{F}$ 1988; 296: 817-9.

13 McNeil BJ, Weichselbaum R, Pauker S. Trade-offs between quality and quantity of life in laryngeal cancer. $N$ Engl f Med 1981; 305: 982-7.

14 Calin A, Elswood J, Rigg S, Skevington S. Ankylosing spondylitis-an analytical review of 1500 patients: the changing pattern of disease. $\mathcal{F}$ Rheumatol $1988 ; 15$ : 1234-8.

15 Sirkin MG. Error effects of survey questionnaires on the public's assessment of health risks. Am $\mathcal{F}$ Public Health 1986; 76: 367-8.

16 Slovic P. Perception of risk. Science 1987; 236: 280-5.

17 O'Brien BJ. What are my chances Doctor? A review of clinical risks. London: Office of Health Economics. 1986.

$18 \mathrm{McNeil}$ BJ, Pauker SG, Sox HC, et al. On the elicitation of preferences for alternative therapies. $N$ Eng $\mathcal{J}$ Med 1982; preferences for $1259-62$. 